\title{
Firm Dynamics and the Origins of Aggregate Fluctuations
}

Stella, Andrea

Please cite paper as:

Stella, Andrea (2015). Firm Dynamics and the Origins of

Aggregate Fluctuations.

International Finance Discussion Papers 1133.

http://dx.doi.org/10.17016/IFDP.2015.1133

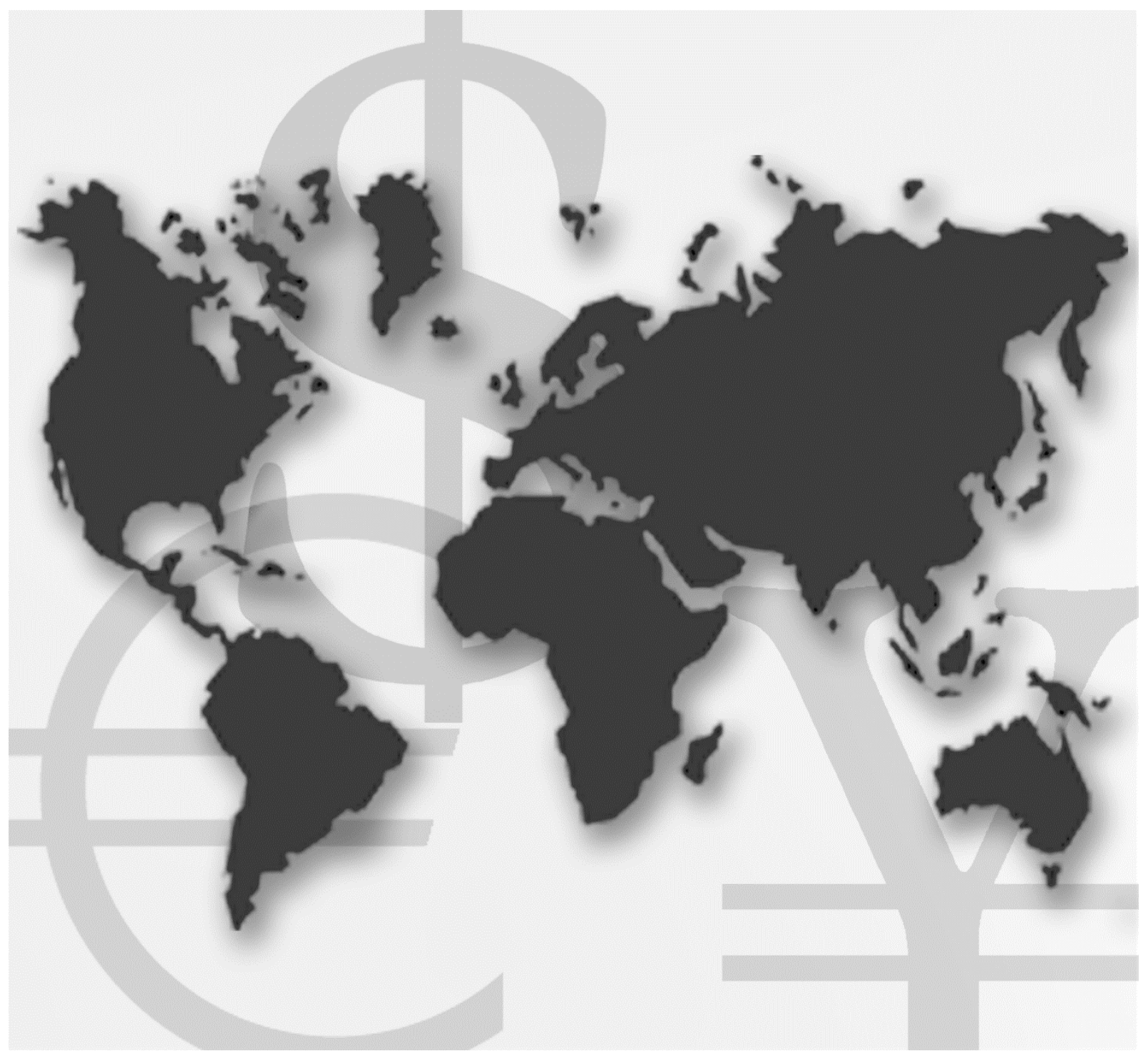

\section{International Finance Discussion Papers}

Board of Governors of the Federal Reserve System

Number 1133

April 2015 
Board of Governors of the Federal Reserve System

International Finance Discussion Papers

Number 1133

April 2015

\title{
Firm Dynamics and the Origins of Aggregate Fluctuations
}

\author{
Andrea Stella
}

NOTE: International Finance Discussion Papers are preliminary materials circulated to stimulate discussion and critical comment. References to International Finance Discussion Papers (other than an acknowledgment that the writer has had access to unpublished material) should be cleared with the author or authors. Recent IFDPs are available on the Web at www.federalreserve.gov/pubs/ifdp/. This paper can be downloaded without charge from the Social Science Research Network electronic library at www.ssrn.com. 


\title{
Firm Dynamics and the Origins of
}

\section{Aggregate Fluctuations}

\author{
Andrea Stella
}

Federal Reserve Board

\begin{abstract}
What drives aggregate fluctuations? I test the granular hypothesis, according to which the largest firms in the economy drive aggregate dynamics, by estimating a dynamic factor model with firm-level data and controlling for the propagation of firm-level shocks using a multi-firm growth model. Each time series, the growth rate of sales of a specific firm, is decomposed in an unobserved common macroeconomic component and in a residual that I interpret as an idiosyncratic firm-level component. The empirical results suggest that, once I control for aggregate shocks, idiosyncratic shocks do not explain much of U.S. GDP growth fluctuations.
\end{abstract}

Keywords: Business Cycles, Firm Dynamics, Granular Residual, Dynamic Factor Models

JEL Codes: E32, D20, C30

*I would like to thank Andrea Ajello, Alberto Alesina, Shai Bernstein, Lorenzo Casaburi, Étienne Gagnon, Stefano Giglio, Illenin Kondo, David Laibson, Jesper Linde, Jacob Leshno, Logan Lewis, Andrew McCallum, Eduardo Morales, Andrea Raffo, Jim Stock, Robert Vigfusson and seminar participants at the Federal Reserve Board, Richmond Fed, GCER, EEA meetings and U.S. Census Bureau for helpful comments. Michael Droste, Alex Harshberger and Rebecca Spavins provided excellent research assistance. The views in this paper are solely the responsibility of the author and should not be interpreted as reflecting the views of the Board of Governors of the Federal Reserve System or of any other person associated with the Federal Reserve System. 


\section{Introduction}

Understanding the origins of aggregate fluctuations is at the core of modern macroeconomics. Theoretically and empirically, macroeconomists have probed in every direction possible to understand what drives the business cycle. Yet we are far from a definite answer. Lucas (1977) was among the first to conjecture the existence of some sort of aggregate shock that hits all sectors at the same time and determines comovement. The subsequent research was unable to empirically identify such an aggregate shock that in some periods boosts the economy and in some other periods depresses it. Recently, interest in business cycle fluctuations has been revived by a very young literature that looks at firms to find answers for aggregate puzzles. ${ }^{1}$ These research efforts have in common the claim that firm-level dynamics matter for the aggregate. To shed light on the role of firms in explaining the business cycle, I analyze firm-level data and study firm dynamics with macro-econometric tools.

I estimate a dynamic factor model with firm-level data so as to be able to identify aggregate and idiosyncratic shocks to firms. Each time series, the growth rate of sales of a specific firm, is decomposed in an unobserved macroeconomic component and in a residual that I interpret as an idiosyncratic firm-level component. The estimation is implemented with Bayesian Markov Chain Monte Carlo methods. By estimating this decomposition I find how much of firm and aggregate dynamics are explained by the firm-level idiosyncratic shocks and how much by the unobserved economy-wide shocks. A simple factor analysis of firm-level data might produce misleading results, since the comovement of firm-level dynamics could be due to the propagation of idiosyncratic shocks. For this reason, I use a

\footnotetext{
${ }^{1}$ See, for instance, Gabaix (2011), Carvalho (2010), Comin and Philippon (2005) and Franco and Philippon (2007).
} 
multi-firm growth model to control for the propagation of shocks through the input-output linkages. My approach sheds light on the origins of aggregate fluctuations and, at the same time, helps us better understand firm dynamics.

The contribution to the literature is twofold. First, most of the previous empirical research addressing the origins of the business cycle used sector-level data from the industrial sectors, ${ }^{2}$ whereas I use firm-level data that spans many different sectors, from manufacturing to financial services, from technology to retailing. Additionally, since the most recent theories stress the importance of firm-level shocks, the use of microeconomic data at the firm-level is both justified and desirable.

Second, I provide evidence against the granular hypothesis, according to which the largest firms in the economy drive aggregate dynamics. I find that firm-level shocks explain most of firm-level dynamics and a little above $20 \%$ of aggregate sale dynamics within my dataset on average. To assess the importance of these shocks in explaining the aggregate fluctuations of the U.S. economy, I estimate how much of GDP growth fluctuations are explained by firm-level idiosyncratic shocks and I find that idiosyncratic shocks have little or no role, depending on the specification, in explaining GDP growth fluctuations. The rest of the paper is organized as follows. Section 2 summarizes three theories on the origins of aggregate fluctuations. Section 3 reviews the previous empirical literature. Section 4 explains how I test the granular hypothesis. Section 5 presents the results of the empirical analysis and section 6 concludes.

\footnotetext{
${ }^{2}$ For instance, Foerster et al. (2011), Shea (2002) and Forni and Reichlin (1998) only use data from the industrial sectors. An important exception is Di Giovanni et al. (2014), who use firm-level data from France.
} 


\section{Three Theories}

The empirical analysis of the business cycle can be traced back to the seminal work of Burns and Mitchell, but still today we do not entirely understand what causes aggregate fluctuations. There are many different theories and I am going to focus on three of them: the first relies entirely on common macroeconomic shocks, whereas the other two involve uncorrelated sectoral and firm-level idiosyncratic shocks. According to the first and most prevalent theory, macroeconomic fluctuations and comovement are due to common macroeconomic shocks. Lucas (1977) was the first to conjecture the existence of an aggregate shock, which hits all sectors in the economy at the same time and determines comovement among them. This intuition was certainly behind the first Real Business Cycle models, where there is one technology shock that hits the representative agent and causes fluctuations.

Since it is hard to observe positive and negative macroeconomic shocks frequent enough to explain the U.S. business cycles, a second theory was developed according to which uncorrelated sectoral shocks are responsible for aggregate fluctuations. Long and Plosser (1983) show that, in a multisector economy with idiosyncratic shocks, business cycles and sectoral comovement naturally emerge from the optimal behavior of utility maximizing agents. The most common critique to theories that attribute aggregate fluctuations to sectoral shocks is simply that truly idiosyncratic shocks should cancel out in the aggregate, the so-called diversification argument. Horvath (1998) extends the analysis of Long and Plosser, showing how sectoral linkages determined by trade can dampen the cancellation of sector-specific shocks. The intuition is that if there is limited interaction among sectors, trade can produce a strong synchronization mechanism; Horvath (2000) calibrates a 
multisector model to U.S. data and shows that implausible aggregate shocks are not necessary to explain the magnitude of aggregate fluctuations in the data. Shea (2002) and Conley and Dupor (2003) present evidence in support of the existence of sectoral complementarities. These papers document a very strong propagation of shocks from one sector to the other. Conley and Dupor (2003) show also that the correlations of sectoral productivities are not entirely due to a common shock.

Acemoglu et al. (2012) offer the most recent research effort in this literature and develop a network approach to the study of aggregate fluctuation. They show that the U.S. economy can be viewed as a network of firms or sectors that interact with each other. The propagation of idiosyncratic shocks depends crucially on the structure of the network: the more asymmetric the network is, the stronger the propagation of idiosyncratic shocks. Sectors are linked because of intersectoral trade and differ in their role as input-suppliers; some sectors play a crucial role by providing general purpose intermediate inputs that are used by most of the other sectors. Idiosyncratic shocks to these "hub" sectors are not entirely cancelled out in the aggregate and propagate causing comovement. Gabaix (2011) develops the third theory on the origins of aggregate fluctuations, the so-called granular hypothesis. He starts from the observation that the distribution of firm size in the U.S. has heavy tails, as shown by Axtell (2001). He then shows that the diversification argument fails if firm size has a fat tail distribution; in an economy where there are $N$ firms subject only to independent firm-level shocks and firm size is distributed according to a power law, aggregate volatility decays according to $\frac{1}{\ln (N)}$, rather than $\frac{1}{\sqrt{N}}$. In this environment idiosyncratic shocks to large firms can produce non-negligible aggregate affects. To prove the importance of idiosyncratic shocks, Gabaix regresses the growth rate of GDP on a weighted average of the demeaned labor productivity of the top 100 firms in 
Compustat finding an $R^{2}$ of one third and concludes that one third of the fluctuations of GDP growth can be explained by idiosyncratic shocks to the top 100 firms. However, Gabaix does not control effectively for common macroeconomic shocks, which could be driving his results. We are therefore left with the empirical question of how much idiosyncratic shocks to large firms can explain of aggregate fluctuations. In this paper I will test the granular hypothesis and I will show that, after controlling for macroeconomic shocks, idiosyncratic shocks to large firms do not have much explanatory power for U.S. GDP growth fluctuations.

\section{Previous Empirical Evidence}

Foerster et al. (2011) take up the challenge of empirically testing the above mentioned three theories of aggregate fluctuations. They show that a structural multisector model with sectoral linkages can produce a simple factor model as a reduced form. Using data on industrial output, they are able to control for sectoral linkages with data from sectoral input-output tables. By calibrating the parameters of the model, the authors are able to separate the common components and the idiosyncratic shocks, which propagate across sectors through trade. The main result of the paper is that even controlling for the propagation of idiosyncratic shocks, aggregate fluctuations are mainly driven by common shocks. They divide the sample in two sub-periods in order to investigate the reasons for the change in aggregate volatility. When they control for sectoral linkages, they find that the Great Moderation seems to be entirely due to a decrease in the volatility of the aggregate shocks; sectoral shocks maintain the same volatility throughout and therefore their contribution to aggregate fluctuations increases during the Great Moderation. The common 
components explain only $50 \%$ of aggregate fluctuations after the 1980 s, leaving the door open for the theories that assign a prominent role to sectoral and firm-level shocks. Atalay (2014) builds on Foerster et al. (2011) using a more flexible model and more data, and finds that sectoral shocks account for nearly two-thirds of the volatility of aggregate output. The paper most closely related to this paper is Di Giovanni et al. (2014). They use data on the universe of French firms to estimate common, sectoral and firm-level shocks in order to assess their importance in explaining aggregate fluctuations. The main difference lies in the nature of the data we use. They have a much wider cross-section, but a much shorter time-series. To control effectively for common macroeconomic shocks, it is crucial to have a rather long time series and a higher frequency than annual. However, it is less important here to have a large cross section, since the theory I am testing is about large firms. Having at most 28 data points per firm, Di Giovanni et al. (2014) have to assume that firms are influenced by macroeconomic shocks in the same way and control for common shocks using fixed effects; since firms are obviously not homogenous in both the direction and the magnitude of their reaction to macro shocks, the residuals in Di Giovanni et al. (2014) might contain unobserved macroeconomic shocks, making their findings hard to interpret, as explained in section 4.1. In section 5, I compare my identification strategy with the one from Di Giovanni et al. (2014) using both quarterly and annual data from Compustat; interestingly, with quarterly data, controlling macroeconomic shocks with time-sector fixed effects seems to be enough to make the granular residual irrelevant in explaining aggregate fluctuations. However, when I use annual frequency data, as Di Giovanni et al. (2014), fixed effects alone do not effectively control for macroeconomic shocks. Di Giovanni et al. (2014) find that firm-level shocks explain most of firm-level dynamics and matter as much as common macroeconomic shocks for aggregate dynamics in France, whereas I find little 
evidence of a role for firm-level shocks in explaining U.S. GDP growth fluctuations. Franco and Philippon (2007) analyze Compustat data using macroeconometric methods. They perform a Blanchard and Quah decomposition on firm-level data and they find that permanent shocks explain around four fifths of firms' dynamics, but are almost uncorrelated with each other and therefore do not contribute much to aggregate fluctuations. Consistently with their findings, I provide evidence that firm-level dynamics are almost entirely explained by firm-level shocks. Alessi et al. (2013) estimate a dynamic factor model using Compustat data and also find that the common component has limited explanatory power for understanding firm-level dynamics. Also related to the analysis conducted in this paper is the literature on longitudinal establishment-level data that shows that idiosyncratic factors seem to explain most of establishment level dynamics. ${ }^{3}$

\section{How to Test the Granular Hypothesis}

\subsection{Model}

I will now describe a simple multi-firm model of the economy, based on the work of Foerster et al. (2011), which will give me some guidance on how to test the theories on the origins of aggregate fluctuations. There are $\mathrm{N}$ firms in the economy, which produce $\mathrm{N}$ different products using capital $K$, labor $L$ and materials $M$; firms use other firms' output as input materials to production. A firm $i$ production function is:

$$
Y_{i t}=A_{i t} K_{i t}^{\alpha_{i}}\left(\prod_{j=1}^{N} M_{i j t}^{\gamma_{i j}}\right) L_{i t}^{1-\alpha_{i}-\sum_{j=1}^{N} \gamma_{i j}}
$$

\footnotetext{
${ }^{3}$ Haltiwanger (1997) provides a review of this literature.
} 
where $\gamma_{i j}$ represents the input share of product $j$ in firm $i$ 's production. Capital evolves according to:

$$
K_{i t+1}=I_{i t}+(1-\delta) K_{i t}
$$

where $I_{i t}$ is the investment in capital made in period $t$ by firm $i$ using its own output $Q_{i t}$ with a constant returns to scale technology: ${ }^{4}$

$$
I_{i t}=Q_{i t}
$$

$A_{i t}$ represents the productivity of firm $i$ in period $t$, which is influenced by both aggregate and firm-level idiosyncratic shocks. I will write compactly the productivities of all firms as a vector $A_{t}=\left(A_{1 t} \ldots A_{N t}\right)$ and I will assume that the logarithm of $A_{t}$ follows a random walk.

$$
\ln A_{t+1}=\ln A_{t}+\epsilon_{t}
$$

where $\epsilon_{t}$ is a vector of firm-level shocks with covariance matrix $\Sigma_{\epsilon}$. The off-diagonal elements of $\Sigma_{\epsilon}$ will be different from zero only if there are aggregate shocks in the economy. In this model, comovement in production is not only due to aggregate shocks, but also to the propagation of shocks from one firm to the other through trade in materials inputs. The model is closed with a description of the representative agent lifetime utility and the

\footnotetext{
${ }^{4}$ For simplicity, I am not allowing firms to use each other's outputs as inputs in the production of capital, as done by Foerster et al. (2011).
} 
economy resource constraint:

$$
\begin{array}{r}
E_{0} \sum_{t=0}^{\infty} \beta_{t} \sum_{i=1}^{N}\left(\frac{C_{i t}^{1-\sigma}-1}{1-\sigma}-\varsigma L_{i t}\right) \\
C_{i t}+\sum_{j=1}^{N} M_{i j t}+Q_{i t}=Y_{i t}
\end{array}
$$

Foerster et al. (2011) show that a linear approximation of the model's first order conditions and resource constraint around the steady state delivers a vector $\operatorname{ARMA}(1,1)$ model for the vector of firm-level output growth, $X_{t}=\left[\Delta \ln \left(Y_{1 t}\right) \ldots \Delta \ln \left(Y_{N t}\right)\right]^{\prime}:^{5}$

$$
(I-\Phi L) X_{t}=\left(\Pi_{0}+\Pi_{1} L\right) \epsilon_{t}
$$

where the parameter matrices $\Phi, \Pi_{0}$ and $\Pi_{1}$ are functions of the parameters of the model. If we assume that firm-level productivity changes are due to both aggregate and idiosyncratic shocks, we can write the vector of innovations to firm-level productivity as a factor model:

$$
\epsilon_{t}=\Lambda F_{t}+v_{t}
$$

where the matrix $\Lambda$ contains the factor loadings, $F_{t}$ and $v_{t}$ are uncorrelated and $\Sigma_{v}$ is a diagonal matrix. If the factor loadings in $\Lambda$ are not all equal, firms respond to aggregate shocks in different ways, which seems realistic; Di Giovanni et al. (2014) do not allow firms to react to aggregate shocks in different ways and therefore might incorrectly estimate the contribution of aggregate shocks in explaining firm and aggregate fluctuations. Combining

\footnotetext{
${ }^{5}$ For a detailed exposition of the model and its solution see the Technical Appendix of Foerster et al. (2011).
} 
(6) and (7), we obtain that the vector of firm-level output growths can be expressed as a factor model:

$$
X_{t}=\Lambda(L) F_{t}+u_{t}
$$

where:

$$
\begin{aligned}
\Lambda(L) & =(I-\Phi L)^{-1}\left(\Pi_{0}+\Pi_{1} L\right) \Lambda \\
u_{t} & =(I-\Phi L)^{-1}\left(\Pi_{0}+\Pi_{1} L\right) v_{t}
\end{aligned}
$$

The vector of firm-level output growths can be written as a factor model with correlated residuals, as the $u_{t}$ 's are linear combinations of the uncorrelated firm-level shocks $v_{t}$ 's. For this reason, if I were to estimate a factor model with firm-level output growths and force the residuals to be uncorrelated, the estimated common component would capture both the aggregate shocks and the propagation of the firm-level idiosyncratic shocks $v_{t}$ 's. If I want to control for the propagation, I can use equation (6) and filter the output growth data:

$$
\epsilon_{t}=\left(\Pi_{0}+\Pi_{1} L\right)^{-1}(I-\Phi L) X_{t}
$$

Unfortunately, I do not have information on output or value added at the firm-level and therefore, like most of the previous literature using firm-level data, I have to work with sales. Let's define the growth rate of sales for firm $i$ in period $t$ as $X_{i t}=\ln \left(Y_{i t} / Y_{i t-1}\right)$, where $Y_{i t}$ are the sales of firm $i$ in period $t$ that are seasonally adjusted, deflated with the GDP deflator and demeaned.

I will first estimate the simple statistical factor model assuming no propagation of shocks. I 
decompose $X_{i t}$ in two components: an economy-wide aggregate unobserved component and a firm-level idiosyncratic component. Both the macroeconomic common component and the firm-level idiosyncratic component are assumed to be autoregressive processes, as I want to allow shocks to have persistent effects. In essence, the dynamic factor model I estimate is:

$$
\begin{aligned}
X_{i t} & =\hat{\Lambda}_{i} G_{t}+u_{i t} & & \\
\Psi^{G}(L) G_{t} & =\nu_{G t} & & \nu_{G t} \sim N\left(0, \sigma_{G}^{2}\right) \\
\Psi_{i}^{x}(L) u_{i t} & =\nu_{i t} & & \nu_{i t} \sim N\left(0, \sigma_{x . i}^{2}\right)
\end{aligned}
$$

where $\Psi^{G}(L)=\left(1-\psi_{G} L\right)$ and $\Psi_{i}^{x}(L)=\left(1-\psi_{x . i} L\right)$.

If the U.S. economy were entirely driven by independent firm-level shocks and there were no propagation of such shocks, there would be no comovement and the common component $G_{t}$ would be equal to zero in (10). However, if there were macro shocks which hit all firms and create comovement among them, this comovement would be picked up by the common component $G_{t}$. The unobserved component would also pick up the comevement due to firm-level shocks that were transmitted from one firm to the other, as explained by the second theory on the origins of aggregate fluctuations. By estimating (10), I would not be able to tell apart how much comovement is due to macroeconomic shocks and how much to the propagation of idiosyncratic shocks.

To control for the propagation of firm-level shocks, I will re-estimate the factor model using the filtered sales growth data $\epsilon_{t}$ from equation (9) instead of the growth rate of sales $X_{t}$. I 
will explain in Section 5.4 how I calibrate the parameters of the model.

$$
\begin{aligned}
\epsilon_{i t} & =\hat{\Lambda}_{\epsilon, i} G_{\epsilon, t}+v_{i t} & & \\
\Psi_{\epsilon}^{G}(L) G_{t} & =\nu_{\epsilon G t} & & \nu_{\epsilon G t} \sim N\left(0, \sigma_{\epsilon G}^{2}\right) \\
\Psi_{\epsilon i}^{x}(L) v_{i t} & =\nu_{\epsilon i t} & & \nu_{\epsilon i t} \sim N\left(0, \sigma_{\epsilon x . i}^{2}\right)
\end{aligned}
$$

where $\Psi_{\epsilon}^{G}(L)=\left(1-\psi_{\epsilon G} L\right)$ and $\Psi_{\epsilon i}^{x}(L)=\left(1-\psi_{\epsilon x . i} L\right)$.

The dynamic factor model (10) incorporates economy-wide aggregate shocks and firm-level idiosyncratic shocks, but does not include group-specific shocks, where the groups can be sectors or geographical regions. In previous versions of the paper, I explored the estimation of models with both economy-wide and sectoral aggregate shocks and the results were similar to the ones I will present later. However the additional layer of sectoral shocks had a significant computational cost and made the estimation algorithm less reliable, as the identification of both economy-wide and sectoral shocks at the same time is not straightforward. For this reason, I decided to exclude group-specific shocks from the model; this choice could lead to an upward bias of the importance of firm-level shocks in explaining aggregate fluctuations.

I estimate (10) and (11) with Markov Chain Monte Carlo methods. I divide the parameters and factors in two blocks. In the first block, I estimate the common factors, $G_{t}$, following the procedure developed by Carter and Kohn (1994), given the time invariant parameters. In the second block, I estimate the time invariant parameters of the unobserved component, $\sigma_{G}^{2}, \psi_{G}$, and the firm-level time invariant parameters $\sigma_{x . i}^{2}, \psi_{x . i}$ and $\Lambda_{i}$, given the common factor $G_{t}$. I first estimate (10) using an unbalanced panel dataset; I estimate 25,000 draws and discard the first 5,000. I then estimate both (10) and (11) with a smaller balanced 
panel; I discovered that with the smaller dataset the Markov Chain needs a higher number of simulations to converge, thus I estimate 100,000 draws and discard the first 50,000. As a robustness check, I estimated the model with more draws and used different starting values and the results were unchanged. The details of the estimation procedure are in the appendix.

I would like to conclude this section noting that the model described earlier has some properties, such as constant returns to scale and perfect competition that are unusual for models describing firm dynamics. However, these properties allow the model to be analytically tractable and provide an excellent framework to control for the propagation of shocks, which is an important component of my empirical exercise.

\subsection{Variance Decomposition}

Variance decomposition at the firm-level follows easily from (10) or (11). I will now explain how I perform the variance decomposition of aggregate sales within my dataset. Following Foerster et al. (2011), I define aggregate sales growth as $\sum_{i} \bar{w}_{i} X_{i t}$, where, as earlier, $X_{i t}=\ln \left(Y_{i t} / Y_{i t-1}\right)$ and $Y_{i t}$ is the seasonally adjusted, deflated with the GDP deflator and

demeaned sales of firm $i$ in period $t$. With this definition, I am focusing on continuing firms and assuming that firm-level weights are constant over time. Excluding the contribution of entering and exiting firms seems to be reasonable, given the evidence in Table 1. Aggregate variance can therefore be written as:

$$
V\left(\sum_{i} \bar{w}_{i} X_{i t}\right)=V\left(\sum_{i} \bar{w}_{i} \hat{\Lambda}_{i} G_{t}+\sum_{i} \bar{w}_{i} u_{i t}\right)
$$


In the same way, I estimate the aggregate variance decomposition with the filtered data $\epsilon_{t}$. From (12), the data, the estimated coefficients and the estimated unobserved components, it is straightforward to derive an aggregate variance decomposition. The variances of the shocks in the model are constant over time, but, since the composition of the economy changes over time because firms enter and exit and since each coefficient and variance is firm-specific, the aggregate variance will necessarily be time-varying. In other words, in each period there will be a different set of firms in the economy and therefore the variance will depend on a different set of coefficients; for these reasons, I compute the aggregate variance at each period and report decade averages.

\subsection{Granular Residual}

Following Gabaix (2011), if idiosyncratic firm-level shocks have an impact on aggregate fluctuations, it should be possible to summarize their contribution with the granular residual:

$$
\Gamma_{t}=\sum_{i}\left[\text { weight }_{i t} \cdot \mu_{i t}\right]
$$

where $\mu_{i t}$ is the idiosyncratic shock that hits firm $i$ in period $t$ and weight $_{i t}$ is the relative weight of firm $i$ in period $t$ in the economy, which can be measured as the ratio of the sales of the firm to aggregate sales. ${ }^{6}$ The estimate of the idiosyncratic shock $\nu_{i t}$ from the dynamic factor analysis described above can be used to compute the granular residual. A

\footnotetext{
${ }^{6}$ The results in the paper are unchanged if I use real GDP instead of aggregate sales to compute the weights.
} 
simple regression of GDP growth can then be run on the granular residual:

$$
\text { GDP Growth }_{t}=\text { constant }+\alpha(L) \Gamma_{t}+\text { residual }_{t}
$$

By estimating equation (14) with OLS, it is possible to determine whether idiosyncratic shocks are important in explaining aggregate fluctuations. I compute the granular residual $\Gamma_{t}$ with the draws of the firm-level idiosyncratic shocks from both the statistical and the structural dynamic factor model estimations.

\section{Results}

\subsection{Data Description}

To test the granular hypothesis, I need data on the largest firms in the economy. Since most of the largest companies in the U.S. are public, I will use the historical Quarterly Compustat North America database, a financial database that contains the balance sheet information of most public companies in the U.S.. The dataset is therefore an unbalanced panel of U.S. public firms that operated between the first quarter of 1962 and the last quarter of 2011. I select the firms that constitute the top 500 in each quarter, a total of 1,610 firms. ${ }^{7}$ The main variable in the analysis is the quarterly growth rate of sales, which is deflated with the GDP deflator and seasonally adjusted with the X12-ARIMA Seasonal Adjustment Program provided by the U.S. Census Bureau. An issue with this dataset is

\footnotetext{
${ }^{7}$ To make my econometric technique feasible, I need each firm to be present in the model for long enough. I therefore keep the top 500 firms in each quarter among those that stay in the sample for at least 10 years. Since most top firms have also a long tenure, this procedure does not differ substantially from selecting the top 500 firms in each quarter. In the appendix, I show that a sample with a 5 year threshold produces similar results.
} 
the selection bias caused by the exclusion of private firms. Due to data limitations, I am forced to use only data on public firms, but this selection bias should not be a significant concern, as most of the largest companies in the U.S. are public and I ultimately want to test a theory on the importance of big firms in explaining the business cycle. ${ }^{8}$ Further details on the construction of the dataset are in the appendix.

To alleviate concerns that my sample is not representative of the largest firms, Figure 5.1 shows that nominal aggregate sales in my dataset are a significant fraction of BEA nominal aggregate sales; since BEA sales include only manufacturing, trade, retail and food services, Figure 5.1 includes only firms that operate in those sectors. Figure 5.2 plots U.S. real GDP growth and the rate of growth of the aggregate real sales of the top 500 firms in each quarter in my dataset and shows that the correlation between the two series is 0.4 .

Figure 5.1: BEA Sales vs Top 500 Sales (in \$Trillion) - Manufacturing, Trade, Retail and Food services

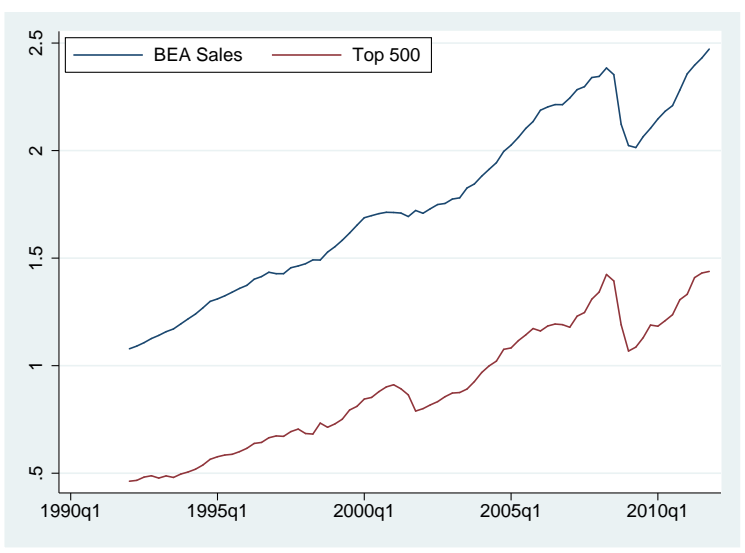

As a first pass at the data, I will decompose aggregate sales growth in three components. Let's define $\hat{Y}_{i t}$ the seasonally adjusted, deflated with the GDP deflator sales of firm $i$ in period $t$, but not demeaned. $\hat{X}_{i t}=100 * \frac{\hat{Y}_{i t}-\hat{Y}_{i t-1}}{\hat{Y}_{i t-1}}$ is the growth rate of sales for firm $i$ in period $t . Z_{t}=\sum_{i} \hat{Y}_{i t}$ is aggregate sales and $g_{t}=100 * \frac{Z_{t}-Z_{t-1}}{Z_{t-1}}$ is aggregate sales growth. At

\footnotetext{
${ }^{8}$ In 2008, the total revenues of the Forbes 441 America's largest private companies were $\$ 1.8$ trillion, whereas the 2009 Fortune 500 public companies produced $\$ 10.7$ trillion in revenues.
} 
Figure 5.2: U.S. Real GDP Growth vs Top 500 Sales' Growth

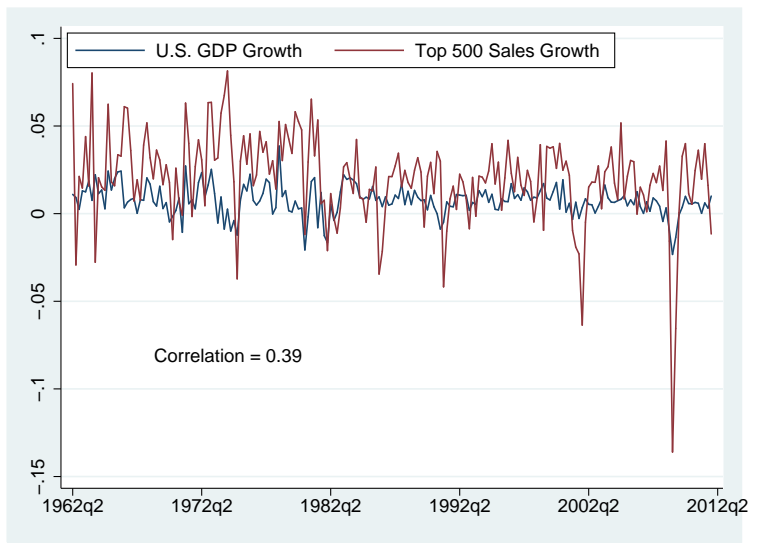

any point in time, I can decompose aggregate sales growth in 3 components:

$$
g_{t}=\sum_{\text {continuing firms }} w_{i t-1} \hat{X}_{i t}+\sum_{\text {entering firms }} \frac{100 * \hat{Y}_{i t}}{Z_{t-1}}-\sum_{\text {exiting firms }} \frac{100 * \hat{Y}_{i t-1}}{Z_{t-1}}
$$

The first component is the contribution to growth of firms that existed in the period before and did not exit. The second component is the contribution of firms that entered the market in period $t$ and finally the third is the contribution of firms that exit the market in period $t-1$. As shown in Table 1, the contribution of continuing firms is what drives aggregate sales growth in the dataset and this evidence allows me to concentrate on continuing firms. ${ }^{9}$ I will control for the propagation of idiosyncratic shocks with the multi-firm growth model described in Section 4.1. Since the model does not allow for entry and exit, I need to use a balanced dataset to filter the growth rates of sales with (9) and estimate equation (11). In order to have enough firms to estimate a factor model, I restrict my attention to those firms that operated from the first quarter of 1970 till the last quarter of 2011, a total of 234 firms. The main variable in the analysis is still the quarterly growth rate of sales, which is

\footnotetext{
${ }^{9}$ The theories I want to test have little to say on firm births and deaths and how they correlate with the business cycle. Moreover, entry and exit in my dataset does not always correspond to firm births and deaths, as entry is due to firms successfully becoming public and exit could be due to privatization.
} 
Table 1: $g_{t}$ and its components

\begin{tabular}{lc}
\hline \hline & Standard Deviation \\
\hline$g_{t}$ & 2.56 \\
Continuing firms & 2.21 \\
Entering firms & 1.02 \\
Exiting firms & 0.52 \\
\hline
\end{tabular}

Source: Compustat and own calculations.

deflated with the GDP deflator and seasonally adjusted. These 234 firms account on average for $45 \%$ of the sales of the 1,610 firms in the unbalanced panel dataset I use in the main analysis. The firms that survive the longest tend to have a larger size and also a lower volatility. On one hand, selecting lower volatility firms could lower the importance of the granular residual; on the other hand, the granular hypothesis predicts that the largest firms should be the most important in explaining aggregate fluctuations.

\subsection{Statistical Factor Analysis}

\subsubsection{Unobserved Component}

Table 2: $G$ on Macro Shocks

\begin{tabular}{|c|c|c|c|c|c|c|}
\hline & All macro shocks & Oil & Monetary & Spending & Taxes & Technology \\
\hline $\operatorname{Adj} R^{2}$ & $\begin{array}{c}7.6 \% \\
(4.6 \%, 10.0 \%)\end{array}$ & $\begin{array}{c}3.2 \% \\
(2.1 \%, 4.4 \%)\end{array}$ & $\begin{array}{c}2.9 \% \\
(1.7 \%, 4.1 \%)\end{array}$ & $\begin{array}{c}0 \% \\
(0 \%, 1.2 \%)\end{array}$ & $\begin{array}{c}0 \% \\
(0 \%, 0 \%)\end{array}$ & $\begin{array}{c}3.1 \% \\
(1.6 \%, 4.4 \%)\end{array}$ \\
\hline
\end{tabular}

I will now present the results of the estimation of (10) on the full unbalanced panel dataset with 1,610 firms. Figure 5.3 shows the estimated mean unobserved common component $G$ 
Figure 5.3: Estimated Unobserved Component

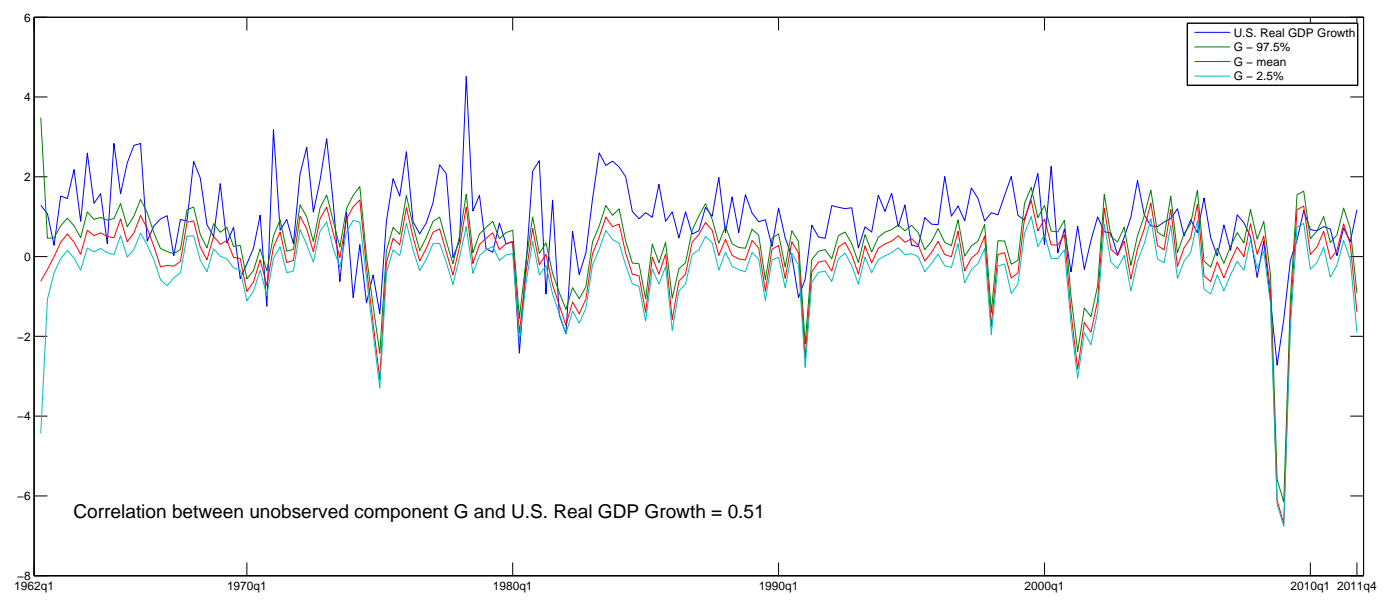

and its $95 \%$ confidence interval together with the U.S. real GDP growth. The correlation between the two series is at 0.51 , which is higher than the correlation of aggregate sales within my dataset with GDP growth. In order to explore such correlation, I regress the estimated mean common component $G$ on five different macroeconomic shocks: oil, technology, monetary, government spending and tax shocks. Following Hamilton (1996), oil shocks are defined as episodes when the oil price exceeds the maximum oil price over the last 12 months; as oil prices, I use the WTI spot prices deflated by the GDP deflator. Technology shocks are computed as in Gali (1999), by imposing long-run restrictions on a bivariate model of productivity and hours. Monetary shocks are computed following Christiano et al. (2005), by estimating a structural VAR with real gross domestic product, real consumption, the GDP deflator, real investment, the real wage, labor productivity, the real interest rate, real profits and the growth rate of M2. Finally the spending and tax shocks are computed with the Blanchard and Perotti (2002) identification procedure. Table 2 summarizes the adjusted $R^{2}$ of the regressions. As expected, the unobserved component 
$G$ is correlated with observable macroeconomic shocks. However, these shocks at most explain $8 \%$ of $G$, leaving most of the variance of the common component unexplained. These results are consistent with the conjecture that some of the comovement of firms in the US economy is due to the propagation of idiosyncratic firm-level or sectoral shocks, which I will explore in Section 5.4.

\subsubsection{Variance Decompositions}

Table 3: Firm-level Variance Decomposition

\begin{tabular}{lccc}
\hline \hline & 5 th Pct & Median & 95 th Pct \\
\hline \multirow{2}{*}{ Macro } & $0.63 \%$ & $3.13 \%$ & $22.91 \%$ \\
& $(0 \%, 3.03 \%)$ & $(0.01 \%, 11.48 \%)$ & $(8.36 \%, 40.41 \%)$ \\
Idio & $77.09 \%$ & $96.87 \%$ & $99.38 \%$ \\
& $(59.59 \%, 91.64 \%)$ & $(88.52 \%, 99.99 \%)$ & $(96.97 \%, 100 \%)$ \\
\hline
\end{tabular}

NOTES: Equation (10) is estimated and a variance decomposition is calculated for each firm. I report in this table the mean share of firm-level variance explained by the observed macroeconomic shocks for the median firm, the firm at 5 th percentile and the firm at $95 \%$ percentile. I do the same for the idiosyncratic shocks. The $90 \%$ Bayesian confidence intervals are in parenthesis.

In Table 3, I report the variance decomposition for the median firm and for the firms at the 5th and 95th percentiles. The unobserved macroeconomic component accounts for less than $5 \%$ of the variation at the firm-level for more than half of the firms in the dataset; for the median firm it explains around 3\% of firm-level dynamics. I find that most firm dynamics are explained by firm-level shocks, which is consistent with previous research, notably Franco and Philippon (2007) and Alessi et al. (2013).

Table 4 shows the variance decomposition of aggregate sales within the dataset. The numbers are broadly in line with previous research: the macroeconomic common component alone accounts on average for almost $80 \%$ of aggregate fluctuations of the top 500 firms. $^{10}$

\footnotetext{
${ }^{10}$ Foerster et al.(2011) find that the common components explain around $80 \%$ of aggregate fluctuations in
} 
Table 4: Variance Decomposition of Aggregate Top 500 Sales

\begin{tabular}{cccccc}
\hline \hline & $1960 \mathrm{~s}$ & $1970 \mathrm{~s}$ & $1980 \mathrm{~s}$ & $1990 \mathrm{~s}$ & $2000 \mathrm{~s}$ \\
\hline \multirow{2}{*}{ Macro } & $76.30 \%$ & $79.98 \%$ & $78.56 \%$ & $76.60 \%$ & $73.37 \%$ \\
& $(68.84 \%, 81.19 \%)$ & $(74.45 \%, 83.81 \%)$ & $(73.25 \%, 82.41 \%)$ & $(71.33 \%, 80.55 \%)$ & $(69.04 \%, 76.92 \%)$ \\
Idio & $23.70 \%$ & $20.02 \%$ & $21.45 \%$ & $23.40 \%$ & $26.63 \%$ \\
& $(18.81 \%, 31.16 \%)$ & $(16.19 \%, 25.55 \%)$ & $(17.59 \%, 26.75 \%)$ & $(19.45 \%, 28.67 \%)$ & $(23.08 \%, 30.96 \%)$ \\
\hline
\end{tabular}

NOTES: Equation (10) is estimated and an aggregate variance decomposition is calculated at each period as explained in Section 4.2. I report in this table the decade average mean estimates.

The $95 \%$ Bayesian confidence intervals are in parenthesis.

There is a sizable portion of aggregate fluctuations of the top 500 firms, above 20\%, that is explained by the residual firm-level shocks, which provides some evidence that within my dataset firm-level idiosyncratic shocks play an important role in explaining aggregate sale dynamics. As explained in Section 4.2, the time variation in the variance decomposition is not due to time-varying variances, as all parameters in the model are time-invariant, but to the time-varying composition of the dataset, caused by the entry and exit of firms. The unobserved common component in Table 4 tends to explain roughly an equal portion of aggregate sale dynamics throughout the sample: on average $79.67 \%$ in the sub-period 1972-1983 and 76.09\% in the sub-period 1984-2007, whereas in Foerster et al. (2011) there is a substantial difference between the two sub-periods. Foerster et al. (2011) estimate their model on two subsamples, whereas the time variation of the variance decomposition in this paper is entirely due to the entry and exit of firms and it is therefore harder to interpret.

\subsubsection{Granular Residual}

I compare the explanatory power of the granular residual computed using the estimated $\nu_{i t}$ from (10) with three benchmarks. First, I will compute the granular residual $\Xi$ using demeaned firm-level revenues growth instead of idiosyncratic shocks, as done by Gabaix 
(2011):

$$
\Xi_{t}=\sum_{i}\left[\text { weight }_{i t} \cdot X_{i t}\right]
$$

where, as earlier, $X_{i t}=\ln \left(Y_{i t} / Y_{i t-1}\right)$ and $Y_{i t}$ is the seasonally adjusted, deflated with the GDP deflator and demeaned sales of firm $i$ in period $t$. Second, I regress $X_{i t}$ on year-2-digit sectors fixed effects, as done by Di Giovanni et al. (2014), and use the residual $\tilde{\zeta}$ to compute the granular residual $\Upsilon$ :

$$
\Upsilon_{t}=\sum_{i}\left[\text { weight }_{i t} \cdot \tilde{\zeta}_{i t}\right]
$$

Third, I regress $X_{i t}$ on quarter-2-digit sectors fixed effects and use the residual $\hat{\zeta}$ to compute the granular residual $\Theta$ :

$$
\Theta_{t}=\sum_{i}\left[\operatorname{weight}_{i t} \cdot \hat{\zeta}_{i t}\right]
$$

Column (1) in Table 5 shows that $\Xi$ can explain about $14 \%$ of GDP growth fluctuations. Columns (2) and (3) show that controlling for macroeconomic shocks with fixed effects is very effective in making the granular residual irrelevant and this is especially true when using quarter fixed effects; in the next subsection, I will show that the same is not true when using annual data on labor productivity. Column (4) contains the results of the granular residual regression (14) using the estimated $\nu_{i t}$ as idiosyncratic shocks. The results suggest that the firm-level idiosyncratic shocks have no direct impact on GDP growth fluctuations. 
Finally, column (5) regresses U.S. GDP growth on the estimated mean unobserved macro component $G$ and shows that the adjusted $R^{2}$ is high at $26 \%$; as already shown in Figure 5.3, the estimated common component is highly correlated with GDP growth.

Table 5: U.S. GDP Growth Regressions

\begin{tabular}{|c|c|c|c|c|c|}
\hline & \multicolumn{5}{|c|}{ Whole Sample } \\
\hline & (1) & $(2)$ & $(3)$ & $(4)$ & $(5)$ \\
\hline & $\Xi$ & $\Upsilon$ & $\Theta$ & $\Gamma$ & $G$ \\
\hline \multirow[t]{2}{*}{ Constant } & 0.009 & 0.008 & 0.007 & 0.0073 & 0.0075 \\
\hline & $(0.007,0.01)$ & $(0.006,0.009)$ & $(0.005,0.009)$ & $(0.0067,0.0079)$ & $(0.0074,0.0076)$ \\
\hline \multirow[t]{2}{*}{$x_{t}$} & 0.12 & 0.07 & -0.005 & 0.01 & 0.042 \\
\hline & $(0.07,0.16)$ & $(0.02,0.13)$ & $(-0.09,0.08)$ & $(-0.03,0.08)$ & $(0.037,0.46)$ \\
\hline \multirow[t]{2}{*}{$x_{t-1}$} & 0.03 & 0.01 & -0.01 & -0.04 & 0.006 \\
\hline & $(-0.01,0.07)$ & $(-0.04,0.06)$ & $(-0.08,0.06)$ & $(-0.07,-0.01)$ & $(0.002,0.010)$ \\
\hline \multirow[t]{2}{*}{$x_{t-2}$} & -0.02 & -0.04 & -0.04 & -0.003 & -0.004 \\
\hline & $(-0.06,0.03)$ & $(-0.09,0.01)$ & $(-0.11,0.03)$ & $(-0.02,0.02)$ & $(-0.007,-0.001)$ \\
\hline \multirow[t]{2}{*}{$\operatorname{Adj} R^{2}$} & 0.14 & 0.04 & 0 & 0 & 0.26 \\
\hline & & & & $(0,0.001)$ & $(0.22,0.29)$ \\
\hline Observations & 197 & 197 & 197 & 197 & 197 \\
\hline
\end{tabular}

NOTES: $x$ is equal to $\Xi, \Upsilon, \Theta, \Gamma$ and $G$, respectively. In the first three column, I regress U.S. GDP Growth on $\Xi, \Upsilon$ and $\Theta$ with OLS and report coefficient estimates and confidence intervals. In columns (4) and (5), Equation (14) is estimated with OLS for each draw of $\Gamma$ and $G$. I report the mean estimate and, in parenthesis, the $95 \%$ Bayesian confidence intervals. 
Table 6: U.S. GDP Growth Regressions

\begin{tabular}{|c|c|c|c|c|}
\hline & \multicolumn{4}{|c|}{ Gabaix Restrictions } \\
\hline & (1) & $(2)$ & $(3)$ & $(4)$ \\
\hline & $\Xi$ & $\Upsilon$ & $\Theta$ & $\Gamma$ \\
\hline \multirow[t]{2}{*}{ Constant } & 0.009 & 0.008 & 0.007 & 0.009 \\
\hline & $(0.007,0.01)$ & $(0.006,0.009)$ & $(0.005,0.008)$ & $(0.008,0.009)$ \\
\hline \multirow[t]{2}{*}{$x_{t}$} & 0.47 & 0.18 & -0.11 & 0.26 \\
\hline & $(0.36,0.57)$ & $(0.04,0.33)$ & $(-0.30,0.06)$ & $(0.16,0.38)$ \\
\hline \multirow[t]{2}{*}{$x_{t-1}$} & 0.16 & 0.05 & -0.07 & 0.12 \\
\hline & $(0.05,0.27)$ & $(-0.09,0.19)$ & $(-026,0.11)$ & $(0.07,0.17)$ \\
\hline \multirow[t]{2}{*}{$x_{t-2}$} & -0.05 & -0.17 & -0.09 & 0.11 \\
\hline & $(-0.15,0.06)$ & $(-0.31,0.02)$ & $(-0.28,-0.09)$ & $(0.06,0.18)$ \\
\hline \multirow[t]{2}{*}{$\operatorname{Adj} R^{2}$} & 0.38 & 0.06 & 0.004 & 0.09 \\
\hline & & & & $(0.05,0.16)$ \\
\hline Observations & 197 & 197 & 197 & 197 \\
\hline
\end{tabular}

NOTES: $x$ is equal to $\Xi, \Upsilon, \Theta$ and $\Gamma$, respectively. In the first three column, I regress U.S. GDP Growth on $\Xi, \Upsilon$ and $\Theta$ with OLS and report coefficient estimates and confidence intervals. In column (4), Equation (14) is estimated with OLS for each draw of $\Gamma$. I report the mean estimate and, in parenthesis, the $95 \%$ Bayesian confidence intervals.

In his granular regressions, Gabaix (2011) removes firms from the oil, energy and finance sectors $^{11}$ and winsorizes growth rates at $20 \%$ in order to drop extraordinary events like

\footnotetext{
${ }^{11}$ Firms from the oil and energy sectors are filtered out because their dynamics are heavily influenced by worldwide commodity prices. Financial firms are excluded because they do not correspond to the description of firm in the model by Gabaix (2011). Gabaix (2011) and I therefore drop firms with SIC codes equal to 2911, 5172, 1311, 4922, 4923, 4924, 1389, between 4900 and 4940 and between 6000 and 7000
} 
mergers and acquisitions. The results by imposing the same restrictions are shown in Table 6. The adjusted $R^{2}$ in all regressions increases. The granular residual computed with revenues explains almost $40 \%$ of GDP growth fluctuations, similar to what Gabaix (2011) finds in his empirical analysis. However, when I control for fixed effects, in columns (2) and (3), or I use my measure of idiosyncratic shocks, in column (4), the fraction of aggregate variance explained by the granular residual diminishes substantially.

Gabaix (2011) computes the granular residual using demeaned labor productivities and not sales growth as I do in this section; in the next subsection, I replicate the regressions run by Gabaix (2011), estimate the dynamic factor model (10) using labor productivities and still reach the same conclusion: controlling for comovement decreases substantially the importance of firm-level shocks in explaining aggregate fluctuations.

\subsection{Annual Labor Productivity}

Gabaix (2011) computes the granular residual using demeaned labor productivities. For this reason, I also estimate the dynamic factor model on labor productivity data.

Compustat provides data on the number of employees only at an annual frequency from 1950 to 2012. The main variable in the analysis is the annual growth rate of labor productivity, where sales are as before deflated with the GDP deflator and only the top 500 firms in each year are included in the dataset. ${ }^{12}$ The dynamic factor procedure works better with higher frequency data, which implies that the results using annual data will have larger confidence intervals. Given the small sample size of the annual labor productivity data, I will not attempt the structural analysis with it. Labor productivity can be

\footnotetext{
${ }^{12}$ As before, to make my econometric technique feasible, I need each firm to be present in the model for long enough. I therefore keep the top 500 firms in each year among those that stay in the sample for at least 20 years. Details on the construction of the dataset are in the appendix.
} 
decomposed in the same way in a macroeconomic component and a firm-level idiosyncratic component, where the growth rate of labor productivity for firm $i$ in period $t$ is computed as $X_{i t}=\ln \left(L P_{i t} / L P_{i t-1}\right)$, where $L P_{i t}$ is the ratio of deflated (with the GDP deflator) and demeaned sales to the number of employees of firm $i$ in period $t$.

Table 7: Firm-level Variance Decomposition

- Labor Productivity

\begin{tabular}{lccc}
\hline \hline & \multicolumn{3}{c}{ Whole Dataset } \\
& 5th Pct & Median & 95 th Pct \\
\hline & & & \\
Macro & $2.04 \%$ & $12.79 \%$ & $69.50 \%$ \\
& & & \\
& $(0 \%, 9.84 \%)$ & $(0.02 \%, 53.89 \%)$ & $(19.21 \%, 96.07 \%)$ \\
Idio & $30.50 \%$ & $87.21 \%$ & $97.96 \%$ \\
& & & \\
& $(3.93 \%, 80.79 \%)$ & $(46.11 \%, 99.98 \%)$ & $(90.16 \%, 100 \%)$ \\
\hline
\end{tabular}

NOTES: Same as Table 3.

The variance decomposition at the firm level, ${ }^{13}$ Table 7 , shows that the common component is able to explain more of firm-level labor productivity dynamics than it does of firm-level sales dynamics, Table 3. However, firm labor productivity dynamics are still dominated by idiosyncratic shocks, as the macro component is able to explain only up to $15 \%$ of firm dynamics for more than half of the firms in my dataset.

\footnotetext{
${ }^{13}$ The variance decomposition of aggregate labor productivity growth is not possible to compute, as total labor productivity is not a simple weighted average of firm-level labor productivities.
} 
Table 8: Regressions - Labor Productivity

\begin{tabular}{|c|c|c|c|c|}
\hline & \multicolumn{4}{|c|}{ Whole Sample } \\
\hline & $(1)$ & $(2)$ & $(3)$ & $(4)$ \\
\hline & $\Xi$ & $\Theta$ & $\Gamma$ & $G$ \\
\hline \multirow[t]{2}{*}{ Constant } & 0.03 & 0.03 & 0.03 & 0.03 \\
\hline & $(0.02,0.04)$ & $(0.027,0.039)$ & $(0.03,0.03)$ & $(0.03,0.03)$ \\
\hline \multirow[t]{2}{*}{$x_{t}$} & 0.48 & 0.88 & 0.12 & 0.06 \\
\hline & $(-0.06,1.02)$ & $(0.39,1.37)$ & $(0.09,0.14)$ & $(0.03,0.15)$ \\
\hline \multirow[t]{2}{*}{$x_{t-1}$} & -0.07 & 0.38 & -0.16 & -0.05 \\
\hline & $(-0.61,0.47)$ & $(-0.11,0.88)$ & $(-0.18,-0.13)$ & $(-0.15,-0.01)$ \\
\hline \multirow[t]{2}{*}{$x_{t-2}$} & -0.33 & -0.19 & 0 & -0.02 \\
\hline & $(-0.85,0.19)$ & $(-0.69,0.31)$ & $(-0.05,0.04)$ & $(-0.05,0.04)$ \\
\hline \multirow[t]{2}{*}{$\operatorname{Adj} R^{2}$} & 0.03 & 0.17 & 0.02 & 0.02 \\
\hline & & & $(0,0.04)$ & $(0,0.04)$ \\
\hline Observations & 56 & 56 & 56 & 56 \\
\hline
\end{tabular}

NOTES: Same as Table 5.

Tables 8 and 9 show the granular regressions. Following Gabaix (2011), in this section I define $\Xi=\sum_{i}\left[\right.$ weight $\left._{i t} \cdot\left(X_{i t}-\bar{X}_{t}\right)\right]$, where I demean individual labor productivity growth rates $X_{i t}$ with the mean productivity growth rate of the top 500 firms in each year $\bar{X}_{t}$; $\Theta$ is computed using the residuals from a regression of $X_{i t}$ on year-sector fixed effects. As shown in Table 8 , in the whole sample, the granular residual is not able to explain much of GDP fluctuations, except for column (2). When I drop firms from the oil, finance and energy 
sectors and observations of growth higher than 20\%, Table 9, I find that the granular residual computed as a weighted average of firm-level labor productivities, $\Xi$, explains close to $30 \%$ of GDP growth fluctuations, as in Gabaix (2011). The granular residual $\Theta$ computed controlling for macroeconomic shocks with fixed effects also has significant explanatory power, as shown in column (2). However, computing the granular residual $\Gamma$ with the estimated firm-level idiosyncratic shocks from the dynamic factor model reduces the adjusted $R^{2}$ to just $6 \%$, as shown in column (3).

Table 9: Regressions - Labor Productivity

\begin{tabular}{|c|c|c|c|}
\hline & \multicolumn{3}{|c|}{ Gabaix Restrictions } \\
\hline & (1) & $(2)$ & $(3)$ \\
\hline & $\Xi$ & $\Theta$ & $\Gamma$ \\
\hline \multirow[t]{2}{*}{ Constant } & 0.03 & 0.03 & 0.03 \\
\hline & $(0.02,0.04)$ & $(0.027,0.037)$ & $(0.03,0.03)$ \\
\hline \multirow[t]{2}{*}{$x_{t}$} & 1.21 & 2.03 & 0.48 \\
\hline & $(0.60,1.82)$ & $(1.15,2.90)$ & $(0.41,0.54)$ \\
\hline \multirow[t]{2}{*}{$x_{t-1}$} & 0.76 & 1.52 & -0.16 \\
\hline & $(0.19,1.33)$ & $(0.61,2.43)$ & $(-0.21,-0.08)$ \\
\hline \multirow[t]{2}{*}{$x_{t-2}$} & 0.30 & 0.69 & 0.13 \\
\hline & $(-0.27,0.88)$ & $(-0.16,1.54)$ & $(-0.02,0.24)$ \\
\hline \multirow[t]{2}{*}{$\operatorname{Adj} R^{2}$} & 0.27 & 0.30 & 0.06 \\
\hline & & & $(0.03,0.09)$ \\
\hline Observations & 56 & 56 & 56 \\
\hline
\end{tabular}

NOTES: Same as Table 6. 


\subsection{Structural Factor Analysis}

I will now use the model described in Section 4.1 to control for the propagation of shocks among firms. As explained above, I will use a balanced subset of the firms in my dataset and filter the growth rates of sales using equation (9). Before I filter the firm-level sales growth data using equation (9), I need to set the parameters of the model described in Section 4.1. I choose the value of the standard parameters following the business cycle literature: $\sigma=1, \varsigma=1, \beta=0.99, \delta=0.025$. I now calibrate the parameters describing the firm-level input-output linkages, the $\gamma_{i j}$ s. I use data from the 1997 BEA Input-Output Use Tables, which contain the use of inputs by industries in producer's prices, and from the Compustat Historical Customer Segments, which provide information on firm linkages. Public firms have to disclose major customers in accordance with Financial Accounting Standards No.131, where a major customer is defined as a firm that purchases more than $10 \%$ of the reporting seller's revenue; unfortunately, firms do not have to report the quantity sold to the customers. ${ }^{14}$

Since I do not have exhaustive data on how much firms within my dataset trade with each other, I need to make some assumptions to combine the sectoral input-output tables and the Compsutat firm-linkages data and provide a calibration of firm-level input-output linkages. I will calibrate the parameters describing the firm-linkages in two different ways. In the first calibration, I assume that each firm accounts for a fraction of the total production in its own sector proportional to its average employment size. I set the input share $\gamma_{i j}$ equal to the dollar payments from the industry of firm $i$ to the industry of firm $j$ expressed as a fraction of the value of production in the sector of firm $i$ times the share of

\footnotetext{
${ }^{14}$ The Compustat data on firm linkages has been used before by the literature, for instance Atalay et al. (2011) and Kelly et al. (2013).
} 
firm $j$ in the total employment of the sector of firm $j .{ }^{15}$ For example, if firm $j$ is in sector $h$ and accounts for $10 \%$ of the total number of sectoral employees and the dollar payments from the industry of firm $i$ to the industry of firm $j$ expressed as a fraction of the value of production in the sector of firm $i$ is 0.5 , then $\gamma_{i j}=0.05 .{ }^{16}$ The intuition is that firm $i$ is buying inputs from sector $h$ and only a fraction of those inputs are produced by firm $j$ : I calibrate such fraction as proportional to the relative size of firm $j$ in sector $h$. In this first calibration, I do not use the data on firm linkages from Compustat.

In the second calibration, I use the linkages data from Compustat to determine which firms are linked. Since I do not have information on the quantities of inputs exchanged, I use the sectoral averages from the BEA input output tables. If Compustat tells me that firm $i$ is a client of firm $j$, I set the input share $\gamma_{i j}$ equal to the dollar payments from the industry of firm $i$ to the industry of firm $j$ expressed as a fraction of the value of production in the sector of firm $i$ times the share of firm $j$ in the total employment of the firms in my dataset belonging to the same sector as firm $j$ that supply to firm $i$ according to the Compustat data on linkages. For example, if firm $i$ is a client of two firms from sector $h, j$ and $k$, firm $j$ accounts for $20 \%$ of the total number of employees between firms $j$ and $k$ (in other words, firm $j$ is a quarter of the size of firm $k$ ), and the dollar payments from the industry of firm $i$ to the industry of firm $j$ expressed as a fraction of the value of production in the sector of firm $i$ is 0.5 , then $\gamma_{i j}=0.1$. In the first calibration, I assume that firms are connected if their respective sectors are and calibrate the input shares using the BEA sectoral

\footnotetext{
${ }^{15}$ I obtained sectoral employment data from the BLS.

${ }^{16}$ There are some firms in my dataset that operate in multiple sectors. Since all firms are assigned to only one sector, the share of such firms in the total employment of their sectors might be overestimated. For three sectors in particular, such shares sum to a number higher than one; the sectors are NAICS $=324,3122,3361$. For those three sectors, I use the share of the employees of the firm in the total employment of the sector within my dataset.
} 
input-output tables; I also assume that each firm is responsible for a fraction of its sector's supply in proportion to its size. In the second calibration, I make use of Compustat data on firm linkages and consider two firms connected only if they are according to Compustat; I then calibrate the input shares using again the BEA sectoral input-output tables, but I change the assumption on how much a firm accounts for its sector's supply by assuming that firms in my dataset buy inputs only from other firms within my dataset.

Table 10: Firm-level Variance Decomposition

\begin{tabular}{|c|c|c|c|}
\hline & No Propagation & Propagation I Calibration & Propagation II Calibration \\
\hline \multirow[t]{2}{*}{ Macro } & $3.76 \%$ & $2.67 \%$ & $3.44 \%$ \\
\hline & $(0.17 \%, 9.64 \%)$ & $(0.04 \%, 8.36 \%)$ & $(0.67 \%, 23.08 \%)$ \\
\hline \multirow[t]{2}{*}{ Idio } & $96.23 \%$ & $97.33 \%$ & $96.56 \%$ \\
\hline & $(90.36 \%, 99.83 \%)$ & $(91.64 \%, 99.96 \%)$ & $(76.92 \%, 99.33 \%)$ \\
\hline
\end{tabular}

Tables 10-12 shows the results of the estimation of both (10) and (11), under the two propagation calibrations. I estimate on the small balanced dataset both the statistical and the structural factor models so as to be able to meaningfully compare how the results change when I control for the propagation of idiosyncratic shocks. Table 10 shows the estimated variance decomposition at the firm-level; the results are very similar to Table 3. It confirms that most firm dynamics are explained by firm-level shocks and, as expected, it is even more true when I control for the propagation of such shocks.

The aggregate variance decomposition in Table 11 shows that with a smaller sample the contribution of firm-level shocks in explaining aggregate sales within the dataset increases. I think that this is due to two reasons. First, it is harder to estimate a common component with a smaller sample, since the common component has a very small role at the firm level, as shown in Tables 3 and 10. The correlation between the unobserved common component 
Table 11: Variance Decomposition of Aggregate Sales

\begin{tabular}{lccc}
\hline \hline & No Propagation & Propagation I Calibration & Propagation II Calibration \\
\hline \multirow{2}{*}{ Macro } & $65.66 \%$ & $58.94 \%$ & $61.74 \%$ \\
\multirow{2}{*}{ Idio } & $(59.93 \%, 70.63 \%)$ & $(51.59 \%, 65.27 \%)$ & $(54.97 \%, 67.56 \%)$ \\
& $34.34 \%$ & $41.06 \%$ & $38.26 \%$ \\
& $(29.37 \%, 40.07 \%)$ & $(34.73 \%, 48.41 \%)$ & $(32.44 \%, 45.03 \%)$ \\
\hline
\end{tabular}

NOTES: Equations (10) and (11) are estimated under the two propagation calibrations and an aggregate variance decomposition is calculated. The $95 \%$ Bayesian confidence intervals are in parenthesis.

estimated with the smaller balanced panel under no propagation is 0.42 , which is smaller than the 0.51 correlation found with the bigger unbalanced panel dataset used earlier. Moreover, idiosyncratic shocks have less of a chance to cancel each other out within a smaller sample. Table 11 also confirms the intuition that some of the macroeconomic component $G$ is explained by the propagation of firm-level shocks: when I control for the propagation of idiosyncratic shocks, the importance of the common component decreases about $7 \%$ with the first calibration and $4 \%$ with the second calibration. However, the propagation of shocks does not seem to explain a whole lot of the common component and this is reflected in the granular residual regressions in Tables 12 and 13.

Table 12 shows the results of the granular residual regressions; In columns (1), I compute the granular residual using demeaned firm-level revenues growth, in column (2) using the the estimated $\nu_{i t}$ from equation (10), in column (3) and (5) using the the filtered $\epsilon_{i t}$ from equation (9) under the two different calibrations of input shares and finally in column (4) and (6) using the the estimated $\nu_{i t}$ from equation (11). In Table 13, I do the same imposing the Gabaix restrictions and therefore removing firms from the oil, energy and finance sectors and winsorizing growth rates at $20 \%$ in order to drop extraordinary events like mergers and acquisitions. 
Table 12: U.S. GDP Growth Regressions

\begin{tabular}{|c|c|c|c|c|c|c|}
\hline & \multicolumn{2}{|c|}{ No Propagation } & \multicolumn{2}{|c|}{ Propagation I Calibration } & \multicolumn{2}{|c|}{ Propagation II Calibration } \\
\hline & (1) & $(2)$ & $(3)$ & (4) & (5) & $(6)$ \\
\hline & $\Xi$ & $\Gamma$ & $\Xi$ & $\Gamma$ & $\Xi$ & $\Gamma$ \\
\hline \multirow[t]{2}{*}{ Constant } & 0.008 & 0.0077 & 0.008 & 0.0075 & 0.008 & 0.0076 \\
\hline & $(0.007,0.009)$ & $(0.0072,0.008)$ & $(0.006,0.008)$ & $(0.0072,0.0078)$ & $(0.006,0.008)$ & $(0.007,0.008)$ \\
\hline \multirow[t]{2}{*}{$x_{t}$} & 0.13 & 0.13 & 0.23 & 0.21 & 0.18 & 0.17 \\
\hline & $(0.08,0.17)$ & $(0.08,0.18)$ & $(0.16,0.31)$ & $(0.13,0.28)$ & $(0.12,0.25)$ & $(0.09,0.24)$ \\
\hline \multirow[t]{2}{*}{$x_{t-1}$} & 0.02 & 0 & 0.03 & 0 & 0.04 & 0.03 \\
\hline & $(-0.02,0.06)$ & $(-0.04,0.03)$ & $(-0.05,0.11)$ & $(-0.06,0.11)$ & $(-0.03,0.11)$ & $(-0.03,0.08)$ \\
\hline \multirow[t]{2}{*}{$x_{t-2}$} & 0.001 & 0.04 & -0.02 & 0.06 & -0.02 & 0.04 \\
\hline & $(-0.04,0.04)$ & $(0,0.08)$ & $(-0.09,0.06)$ & $(0.01,0.11)$ & $(-0.08,0.05)$ & $(-0.01,0.09)$ \\
\hline \multirow[t]{2}{*}{$\operatorname{Adj} R^{2}$} & 0.23 & 0.05 & 0.23 & 0.05 & 0.19 & 0.03 \\
\hline & & $(0.01,0.11)$ & & $(0.01,0.11)$ & & $(0,0.08)$ \\
\hline Observations & 163 & 163 & 163 & 163 & 163 & 163 \\
\hline
\end{tabular}

NOTES: In odd numbered columns, I regress U.S. GDP Growth on $\Xi$ with OLS and report coefficient estimates and confidence intervals. In even numbered columns, Equation (14) is estimated with OLS for each draw of $\Gamma$. I report the mean estimate and, in parenthesis, the $95 \%$ Bayesian confidence intervals.

The granular residual regressions show that controlling for the propagation of idiosyncratic shocks increases the estimated impact of idiosyncratic shocks on U.S. GDP growth fluctuations. Table 12 and especially Table 13 point at a higher contribution of firm-level shocks to aggregate fluctuations than Table 5. Since the increase in the importance of the granular residual happens in both the statistical factor analysis, column (2), and the 
structural factor analyses, columns (4) and (6), it must be at least in part due to the smaller size of the sample. The fewer the firms, the less precise will be the estimation of the common macroeconomic component. However, in both the statistical and the structural estimations, the adjusted $R^{2}$ always substantially decreases going from using $\Xi$ to $\Gamma$; in other words, when I remove the comovement due to macroeconomic shocks in computing the granular residual, the idiosyncratic firm-level shocks have a much smaller impact on U.S. aggregate fluctuations.

Table 13: Gabaix Restrictions

\begin{tabular}{|c|c|c|c|c|c|c|}
\hline & \multicolumn{2}{|c|}{ No Propagation } & \multicolumn{2}{|c|}{ Propagation I Calibration } & \multicolumn{2}{|c|}{ Propagation II Calibration } \\
\hline & $(1)$ & $(2)$ & $(3)$ & $(4)$ & $(5)$ & $(6)$ \\
\hline & $\Xi$ & $\Gamma$ & $\Xi$ & $\Gamma$ & $\Xi$ & $\Gamma$ \\
\hline \multirow[t]{2}{*}{ Constant } & 0.008 & 0.0077 & 0.008 & 0.0078 & 0.008 & 0.008 \\
\hline & $(0.007,0.009)$ & $(0.0074,0.008)$ & $(0.007,0.009)$ & $(0.0075,0.0082)$ & $(0.007,0.009)$ & $(0.0077,0.0083)$ \\
\hline \multirow[t]{2}{*}{$x_{t}$} & 0.33 & 0.25 & 0.49 & 0.47 & 0.44 & 0.42 \\
\hline & $(0.26,0.41)$ & $(0.20,0.30)$ & $(0.38,0.60)$ & $(0.38,0.54)$ & $(0.34,0.54)$ & $(0.34,0.48)$ \\
\hline \multirow[t]{2}{*}{$x_{t-1}$} & 0.11 & 0.08 & 0.15 & 0.16 & 0.21 & 0.23 \\
\hline & $(0.03,0.19)$ & $(0.04,0.11)$ & $(0.04,0.27)$ & $(0.10,0.21)$ & $(0.10,0.31)$ & $(0.18,0.28)$ \\
\hline \multirow[t]{2}{*}{$x_{t-2}$} & 0.07 & 0.13 & 0.03 & 0.19 & 0.07 & 0.18 \\
\hline & $(-0.13,0.14)$ & $(0.09,0.16)$ & $(-0.08,0.14)$ & $(0.15,0.23)$ & $(-0.02,0.18)$ & $(0.15,0.21)$ \\
\hline \multirow[t]{2}{*}{$\operatorname{Adj} R^{2}$} & 0.38 & 0.18 & 0.43 & 0.26 & 0.40 & 0.26 \\
\hline & & $(0.12,0.24)$ & & $(0.17,0.33)$ & & $(0.18,0.33)$ \\
\hline Observations & 163 & 163 & 163 & 163 & 163 & 163 \\
\hline
\end{tabular}

NOTES: Same as Table 12. 
A caveat is that I do not have full information on firm linkages and therefore need to make some coarse assumptions on how sectoral trade translates into firm-to-firm trade. However, it is not clear whether the true firm-level linkages would necessarily imply a higher transmission of shocks: in the first calibration, I impose trade to happen between two firms as long as their sectors trade, whereas in reality this does not have to be true; in the second calibration, I use information on the actual firm-linkages within my dataset and the results from Tables 10-12 seem to suggest that using more precise data on firm linkages decreases the estimated propagation of shocks instead of increasing it. All told, I interpret my results as providing evidence that the impact of idiosyncratic shocks to the top firms in the economy on aggregate fluctuations is at best very small.

These results seem to be in conflict with Table 2, which shows that the estimated common component $G$ is only in small part explained by macroeconomic shocks. I believe that there is no conflict; my estimation procedure controls for the propagation of firm-level shocks only within my sample, but allows the comovement of firms within my sample to be due to the propagation of shocks from all the firms outside of the sample. It is entirely possible that aggregate fluctuations are in part due to the propagation of firm-level or sectoral shocks and, at the same time, shocks to the top firms in the economy do not have by themselves a significant impact. In other words, I interpret my results as rejecting Gabaix's conjecture that shocks to the top firms explain around a third of aggregate fluctuations, but not necessarily rejecting the second theory explained in Section 2 on how propagation of sectoral and firm-level idiosyncratic shocks can influence aggregate fluctuations. Foerster et al. (2011) show that, at least in the second part of their sample, an important fraction of the comovement of sectoral IPs was due to the propagation of idiosyncratic shocks. Future empirical research will hopefully explore further this promising alternative theory of the 
origins of aggregate fluctuations.

\section{Concluding Remarks}

Most macroeconomists would claim that the business cycle is entirely driven by aggregate macroeconomic shocks. There are several theoretical explanations for how microeconomic shocks can have an impact on the aggregate economy, but there is still very little empirical evidence for these theories. Most of the evidence on the origins of aggregate fluctuations comes from the analysis of aggregate data or sector-level data.

I estimate a dynamic factor model using firm-level data and I find that idiosyncratic shocks to firms do no have a substantial direct impact on aggregate fluctuations. Gabaix (2011) finds that around a third of U.S. GDP growth fluctuations are explained by firm-level idiosyncratic shocks. I revisit his result, finding that idiosyncratic firm-level shocks explain most of firm dynamics in my dataset, but have little role in explaining GDP growth fluctuations.

\section{References}

[1] Acemoglu, D., Carvalho, V. M., Ozdaglar, A., and Tahbaz-Salehi, A. (2012), "The Network Origins of Aggregate Fluctuations", Econometrica, 80(5), 1977-2016.

[2] Alessi, L., Barigozzi, M. and Capasso, M. (2013), "The Common Component of Firm Growth", Structural Change and Economic Dynamics, 26, 7382.

[3] Atalay, E., Hortaçsu, A., Roberts, J., and Syverson, C. (2011), "Network Structure of Production", PNAS, 108(3), 5199-5202. 
[4] Atalay, E. (2014), "How Important Are Sectoral Shocks", working paper.

[5] Axtell, R. L. (2001), "Zipf Distribution of U.S. Firm Sizes", Science, CCXCIII, 1818-1820.

[6] Blanchard, O. and Perotti, R. (2002), "An Empirical Characterization of the Dynamic Effects of Changes in Government Spending and Taxes in Output", Quarterly Journal of Economics, 117(4), 1329-1368.

[7] Blanchard, O. and Quah, D. (1989), "The Dynamic Effects of Aggregate Demand and Supply Disturbances", The American Economic Review, 79(4), 655-673.

[8] Burns, A. F. and Mitchell, W. C. (1946), "Measuring Business Cycles", National Bureau of Economic Research.

[9] Carter, C.K. and Kohn, R. (1994), "On Gibbs Sampling for State Space Models", Biometrika, 81(3), 541-553.

[10] Carvalho, V. M. (2010), "Aggregate Fluctuations and the Network Structure of Intersectoral Trade", working paper.

[11] Carvalho, V. M. and Gabaix, X. (2013), "The Great Diversification and its Undoing", American Economic Review, 103(5), 1697-1727.

[12] Chib, S. and Greenberg, E. (1994), "Bayes Inference in Regression Models with $\operatorname{ARMA}(\mathrm{p}, \mathrm{q})$ Errors", Journal of Econometrics, 64, 183-206.

[13] Christiano, L. J., Eichenbaum, M. and Evans, C. L. (2005), "Nominal Rigidities and the Dynamic Effects of a Shock to Monetary Policy", Journal of Political Economy, 113(1), 1-45. 
[14] Comin, D. and Philippon, T. (2005), "The Rise in Firm-Level Volatility: Causes and Consequences", NBER Macroeconomics Annual, 20, 167-201.

[15] Conley, T. G. and Dupor, B. (2003), "A Spatial Analysis of Sectoral Complementarity", Journal of Political Economy, 111(2), 311-352.

[16] Di Giovanni, J., Levchenko, A. and Mejean, I. (2014), "Firms, Destinations, and Aggregate Fluctuations", Econometrica, 82(4), 1303-1340.

[17] Franco, F. and Philippon, T. (2007), "Firms and Aggregate Dynamics", The Review of Economics and Statistics, 89(4), 587-600.

[18] Foerster, A. T., Sarte, P. G. and Watson, M. W. (2011), "Sectoral versus Aggregate Shocks: A Structural Factor Analysis of Industrial Production", Journal of Political Economy, 119(1), 1-38.

[19] Forni, M. and Richlin, L. (1998), "Let's Get Real: A Factor Analytical Approach to Disaggregated Business Cycle Dynamics", The Review of Economic Studies, 65(3), 453-473.

[20] Gabaix, X. (2011), "The Granular Origins of Aggregate Fluctuations", Econometrica, 79, 733-772.

[21] Gali, J. (1999), "Technology, Employment, and the Business Cycle: Do Technology Shocks Explain Aggregate Fluctuations?", American Economic Review, 89(1), 249-271. 
[22] Haltiwanger, J. (1997), "Measuring and Analyzing Aggregate Fluctuations: The Importance of Building from Microeconomic Evidence", Federal Reserve Bank of St. Louis Review, May-June, 55-77.

[23] Hamilton, J. D. (1996), "This is what happened to the oil price-macroeconomy relationship", Journal of Monetary Economics, 38(2), 215-220.

[24] Horvath, M. (1998), "Cyclicality and Sectoral Linkages: Aggregate Fluctuations from Independent Sectoral Shocks", Review of Economic Dynamics, 1, 781-808.

[25] Horvath, M. (2000), "Sectoral Shocks and Aggregate Fluctuations", Journal of Monetary Economics, 45, 69-106.

[26] Kelly, B, Lustig, H. and Van Nieuwerburgh, S. (2013), "Firm Volatility in Granular Networks", working paper.

[27] Long, J. B. Jr. and Plosser, C. I. (1983), "Real Business Cycles", Journal of Political Economy, 91(1), 39-69.

[28] Long, J. B. Jr. and Plosser, C. I. (1987), "Sectoral vs. Aggregate Shocks In The Business Cycle", AEA Papers and Proceedings, 77(2), 333-336.

[29] Lucas, R. E. (1977), "Understanding Business Cycles", Carnegie-Rochester Conference Series on Public Policy, 5, 7-29.

[30] Moench, E., Ng, S. and Potter, S. (forthcoming), "Dynamic Hierarchical Factor Models", Review of Economics and Statistics.

[31] Shea, J. (2002), "Complementarities and Comovement", Journal of Money, Credit and Banking, 34(2), 412-433. 
[32] Vigfusson, R. (2008), "How Does the Border Affect Productivity? Evidence from American and Canadian Manufacturing Industries", Review of Economics and Statistics, 90(1), 49-64. 


\section{Appendices}

\section{A Data Appendix}

\section{A.1 Quarterly Revenues}

Data comes from the historical quarterly Compustat North America database, a financial database that contains the balance sheet information of most public companies in the U.S. The dataset is therefore an unbalanced panel of U.S. public firms that operated between the first quarter of 1962 and the last quarter of 2011. The following steps are taken before the empirical analysis:

i I keep only firms incorporated in the U.S. with revenues denominated in dollars. ${ }^{17}$

ii I drop negative sales and firms with nonconsecutive data points. In order to estimate the dynamic factor model, I cannot have nonconsecutive observations.

iii I select the top 500 firms in each period based on the previous period sales out of those that have been in the dataset for at least 10 consecutive years. ${ }^{18}$ I need firms to be in the dataset for long enough to estimate the dynamic factor model. If there are less than 500 firms in a period, I keep all the firms.

iv I seasonally adjust revenues using the X12-ARIMA Seasonal Adjustment Program provided by the U.S. Census Bureau (implemented by STATA).

v I make revenues real using the GDP deflator.

\footnotetext{
${ }^{17}$ Some firms engage in foreign trade and therefore a fraction of the sales in the dataset are not domestic, but are all denominated in dollars.

${ }^{18}$ In the appendix, I show that a sample with a 5 year threshold produces similar results.
} 
vi I check for non-stationarity using a simple Dickey-Fuller test on the rate of growth of revenues of all firms and I drop 3 firms that have non-stationary revenues' growth.

vii I de-mean the rate of growth of revenues of each firm by subtracting the mean growth rate of the firm over the sample.

\section{A.2 Annual Labor Productivities}

Data comes from the historical annual Compustat North America database, a financial database that contains the balance sheet information of most public companies in the U.S.. The dataset is therefore an unbalanced panel of U.S. public firms that operated between 1950 and 2012. The following steps are taken before the empirical analysis:

i I keep only firms incorporated in the U.S. with revenues denominated in dollars. ${ }^{19}$

ii I drop negative sales and firms with nonconsecutive data points. In order to estimate the dynamic factor model, I cannot have nonconsecutive observations.

iii I check for non-stationarity using a simple Dickey-Fuller test on the rate of growth of revenues of all firms and I drop firms that have non-stationary revenues' growth.

iv I select the top 500 firms in each period based on the previous period sales out of those that have been in the dataset for at least 20 consecutive years. I need firms to be in the dataset for long enough to estimate the dynamic factor model. If there are less than 500 firms in a period, I keep all the firms.

v I make revenues real using the GDP deflator.

\footnotetext{
${ }^{19}$ Some firms engage in foreign trade and therefore a fraction of the sales in the dataset are not domestic, but are all denominated in dollars.
} 
vi I compute labor productivity as the ratio of real revenues to number of employees.

vii I de-mean the rate of growth of labor of productivity of each firm by subtracting the mean growth rate of the firm over the sample.

\section{B Model Estimation}

I estimate a dynamic factor model with a Metropolized Gibbs sampling procedure. I divide the parameters and factors in two blocks. In the first block, I estimate the common factor, $G_{t}$, following the procedure developed by Carter and Kohn (1994), given the time invariant parameters. In the second block, I estimate the time invariant parameters of the common component, $\sigma_{G}, \psi_{G}$, and the firm-level time invariant parameters $\sigma_{x . i}, \psi_{x . i}$ and $\Lambda_{i}$, given the common factor $G_{t}$. A common issue of identification arises in the estimation of the model. The scales of the factor $G_{t}$ and its loadings $\Lambda_{i}$ are not separately identified; I adopt the standard normalization of fixing the variance of the common factors $G_{t}$ to a constant. ${ }^{20}$

\section{B.1 I Block}

Given the time invariant parameters, I can sample $G_{t}$ following Carter and Khon (1994).

Let's define $\tilde{X}_{i t}=\Psi_{i}^{x}(L) X_{i t}, \tilde{\Lambda}_{i}(L)=\Psi_{i}^{x}(L) \Lambda_{i}$. I can then write:

$$
\begin{aligned}
G_{t} & =\psi_{G} G_{t-1}+\nu_{G t} \\
\tilde{X}_{i t} & =\tilde{\Lambda}_{i}(L) G_{t}+\nu_{i t}
\end{aligned}
$$

\footnotetext{
${ }^{20} \mathrm{I}$ choose the constant to be equal to $10^{-2}$, which is in the order of magnitude of the average variance of the $X_{i t}$.
} 
Stacking the lags of $G_{t}, \vec{G}_{t}=\left(\begin{array}{ll}G_{t} & G_{t-1}\end{array}\right)^{\prime}$, let's define $\overrightarrow{\tilde{\Lambda}}_{i}=\left[\begin{array}{ll}\tilde{\Lambda}_{i .0} & \tilde{\Lambda}_{i .1}\end{array}\right], \vec{\nu}_{G t}=\left(\begin{array}{ll}\nu_{G t} & 0\end{array}\right)^{\prime}$ and $\vec{\psi}_{G}=\left[\begin{array}{cc}\psi_{G} & 0 \\ 1 & 0\end{array}\right]$ I get:

$$
\begin{aligned}
\vec{G}_{t} & =\vec{\psi}_{G} \vec{G}_{t-1}+\vec{\nu}_{G t} \\
\tilde{X}_{i t} & =\overrightarrow{\tilde{\Lambda}}_{i} \vec{G}_{t}+\nu_{i t}
\end{aligned}
$$

I then run the Kalman filter forward to obtain estimates of $\vec{G}_{T \mid T}:^{21}$

$$
\begin{aligned}
\vec{G}_{t+1 \mid t} & =\vec{\psi}_{G} \vec{G}_{t \mid t} \\
\vec{P}_{G t+1 \mid t} & =\vec{\psi}_{G} \vec{P}_{G t \mid t} \vec{\psi}_{G}^{\prime}+\vec{\Sigma}_{G} \\
\vec{G}_{t \mid t} & =\vec{G}_{t \mid t-1}+\vec{P}_{G t \mid t-1} \overrightarrow{\tilde{\Lambda}}_{i}^{\prime}\left(\overrightarrow{\tilde{\Lambda}}_{i} \vec{P}_{G t \mid t-1} \overrightarrow{\tilde{\Lambda}}_{i}^{\prime}+\Sigma_{x i}\right)^{-1}\left(\tilde{X}_{i t}-\overrightarrow{\tilde{\Lambda}}_{i} \vec{G}_{t \mid t-1}\right) \\
\vec{P}_{G t \mid t} & =\vec{P}_{G t \mid t-1}-\vec{P}_{G t \mid t-1} \overrightarrow{\tilde{\Lambda}}_{i}^{\prime}\left(\overrightarrow{\tilde{\Lambda}}_{i} \vec{P}_{G t \mid t-1} \overrightarrow{\tilde{\Lambda}}_{i}^{\prime}+\Sigma_{x i}\right)^{-1} \overrightarrow{\tilde{\Lambda}}_{i} \vec{P}_{G t \mid t-1} \\
\vec{G}_{T} \mid \Omega_{G} & \sim N\left(\vec{G}_{T \mid T}, \vec{P}_{G T \mid T}\right)
\end{aligned}
$$

Then for $t=T-1, \ldots, 1$ I can generate draws $\vec{G}_{t}$ from:

$$
\vec{G}_{t} \mid \vec{G}_{t+1}^{*}, \Omega_{G} \sim N\left(\vec{G}_{t \mid t, G_{t+1}^{*}}, \vec{P}_{G t \mid t, G_{t+1}^{*}}\right)
$$

\footnotetext{
${ }^{21}$ Since the dataset is an unbalanced panel, each time series, the growth rate of revenues of a firm, has some missing observations either at the beginning or at the end of the sample (or both). The missing observations contain no new information and therefore do not contribute to the estimation of the common component.
} 


$$
\begin{aligned}
\vec{G}_{t \mid t, \vec{G}_{t+1}^{*}} & =\vec{G}_{t \mid t}+\vec{P}_{G t \mid t} \vec{\psi}_{G}^{\prime}\left(\vec{\psi}_{G} \vec{P}_{G t \mid t-1} \vec{\psi}_{G}^{\prime}+\Sigma_{G}\right)^{-1}\left(\vec{G}_{t+1}^{*}-\overrightarrow{\tilde{\psi}}_{G}^{*} \vec{G}_{t \mid t}\right) \\
\vec{P}_{G t \mid t, \vec{G}_{t+1}^{*}} & =\vec{P}_{G t \mid t}-\vec{P}_{G t \mid t} \vec{\psi}_{G}^{* \prime}\left(\vec{\psi}_{G}^{*} \vec{P}_{G t \mid t-1} \vec{\psi}_{G}^{* \prime}+\Sigma_{G}\right)^{-1} \vec{\psi}_{G}^{*} \vec{P}_{G t \mid t-1}
\end{aligned}
$$

where $\vec{G}_{t+1}^{*}$ and $\vec{\psi}_{G}^{*}$ are the first rows of $\vec{G}_{t+1}$ and $\vec{\psi}_{G}$.

\section{B.2 II Block}

Given the common factors $G_{t}$, the model reduces to a system of independent regression equations with autocorellated errors. I follow the procedure developed by Chib and Greenberg (1994) to estimate the sectoral-specific and the firm-specific parameters. The

prior for the coefficients, $\Lambda_{i}, \psi_{G}$ and $\psi_{x . i}$ are normals with zero mean and variance equal to $10^{-1}$. The prior for the variances $\sigma_{G}^{2}$ and $\sigma_{x . i}^{2}$ are inverse gammas, $\operatorname{IG}\left(1,10^{-3}\right)$. I will here describe only the procedure to estimate the firm-level parameters, as the procedure to estimate the parameters of the common component is equivalent. For this subsection I will change some notation: $\tilde{y}_{i t}=X_{i t}, \tilde{x}_{i t}=G_{t}, \beta_{i}=\Lambda_{i}, \psi_{i}=\psi_{x . i}, \sigma_{i}=\sigma_{x . i}$ and $\Psi_{i}=1-\psi_{x . i}$. Let's now define $\Sigma_{i}=\left(1 /\left(1-\psi_{x . i}^{2}\right)\right)$ and $Q_{i} Q_{i}^{\prime}=\Sigma_{i}, \tilde{y}_{i, 1}^{*}=Q_{i}^{-1} \tilde{y}_{i 1}, \tilde{x}_{i, 1}^{*}=Q_{i}^{-1} \tilde{x}_{i 1}, \tilde{y}_{i}^{*}=\left[\tilde{y}_{i, 1}^{*}\right.$ $\left.\tilde{y}_{i, 2}^{*}\right]^{\prime}$ where $\tilde{y}_{i, 2}^{*}$ is a $((T-1) \times 1)$ vector with $t$ th row equal to $\Psi_{i} \tilde{y}_{i t}$, and $\tilde{x}_{i}^{*}=\left[\tilde{x}_{i, 1}^{*} \tilde{x}_{i, 2}^{*}\right]^{\prime}$, where $\tilde{x}_{i, 2}^{*}$ is a $((T-1) \times 2)$ vector with $t$ th row equal to $\left[\Psi_{i} \Psi_{i} \tilde{x}_{i t}\right]$. Finally, $e_{i t}$ is equal to $\tilde{y}_{i t}-\tilde{x}_{i t}^{\prime} \beta_{i}, e_{i}=\left(\begin{array}{lll}e_{i 2} & \ldots & e_{i T}\end{array}\right)$ is a $((T-1) \times 1)$ vector, and $E=e_{1}$ is a $((T-1) \times 1)$ vector. 
The conditional posterior distributions of the parameters are:

$$
\begin{aligned}
\beta_{i} \mid y_{i}, \Psi_{i}, \sigma_{i}^{2} \sim N\left(V_{\beta_{i}}^{-1}\left(\sigma_{i}^{-2} \tilde{x}_{i}^{* \prime} \tilde{y}_{i}^{*}\right), V_{\beta_{i}}^{-1}\right) \\
\psi_{i} \mid y_{i}, \beta_{i}, \sigma_{i}^{2} \sim \Phi(\psi) \times N\left(\hat{\psi}, V_{\psi}^{-1}\right) I_{\psi} \\
\sigma_{i}^{2} \mid y_{i}, \beta_{i}, \Psi_{i} \sim \operatorname{IG}\left(\frac{1+T}{2}, \frac{10^{-3}+d_{i}}{2}\right)
\end{aligned}
$$

where $V_{\beta_{i}}=\left(1+\sigma_{i}^{-2} \tilde{x}_{i}^{* \prime} \tilde{x}_{i}^{*}\right), V_{\psi}=\left(1+\sigma_{i}^{-2} E_{i}^{\prime} E_{i}\right), I_{\psi}$ is an indicator function for stationarity, $\hat{\psi}=V_{\psi}^{-1} \sigma_{i}^{-2} E_{i}^{\prime} e_{i}, d_{i}=\left\|\tilde{y}_{i}^{*}-\tilde{x}_{i}^{*} \beta_{i}\right\|$ and finally $\Phi(\psi)=|\Sigma|^{-1 / 2} \exp \left[-\frac{1}{2 \sigma_{i}^{2}}\left(\tilde{y}_{i, 1}-\tilde{x}_{i, 1} \beta_{i}\right) \Sigma^{-1}\left(\tilde{y}_{i, 1}-\tilde{x}_{i, 1} \beta_{i}\right)\right]$. It is easy to draw from the distributions of $\beta_{i}$ and $\sigma_{i}^{2}$. Following Chib and Greenberg (1994), I sample from the posterior distribution of $\psi$ using a Metropolis-Hastings algorithm. I draw $\psi^{\text {new }}$ from $N\left(\hat{\psi}, V_{\psi}^{-1}\right) I_{\psi}$ and then I accept it as the next sample value with probability $\min \left(\frac{\Phi\left(\psi^{\text {new }}\right)}{\Phi\left(\psi^{\text {old }}\right)}, 1\right)$; if $\psi^{\text {new }}$ is rejected, the new sample value remains the previous iteration value, $\psi^{\text {old }}$.

\section{Robustness}

\section{C.1 5 year tenure - Quarterly Revenues}

In order to check the robustness of the results to including firms that stay in the dataset for less then 10 years, I re-run the empirical exercises by lowering the tenure threshold to 5 years. In other words, I select the top 500 firms in each period based on the previous period sales out of those that have been in the dataset for at least 5 consecutive years. The results 
of the variance decompositions and the granular residual regressions are summarized in the following three tables. The results are very similar to the baseline results, but the confidence intervals are wider as you would expect with less firm-level observations.

Table 14: Firm-level Variance Decomposition

\begin{tabular}{lccc}
\hline \hline & \multicolumn{3}{c}{ Whole Dataset } \\
& 5th Pct & Median & 95th Pct \\
\hline \multirow{2}{*}{ Macro } & $1.17 \%$ & $5.71 \%$ & $30.43 \%$ \\
& $(0.01 \%, 6.00 \%)$ & $(0.08 \%, 29.79 \%)$ & $(5.06 \%, 77.35 \%)$ \\
Idio & $69.57 \%$ & $94.30 \%$ & $98.83 \%$ \\
& $(22.65 \%, 94.94 \%)$ & $(70.21 \%, 99.99 \%)$ & $(94.00 \%, 100 \%)$ \\
\hline \multicolumn{2}{l}{ NOTES: Same as Table 3.}
\end{tabular}

Table 15: Aggregate Variance Decomposition

\begin{tabular}{lccccc}
\hline \hline & $1960 \mathrm{~s}$ & $1970 \mathrm{~s}$ & $1980 \mathrm{~s}$ & $1990 \mathrm{~s}$ & $2000 \mathrm{~s}$ \\
\hline \multirow{2}{*}{ Macro } & $70.20 \%$ & $77.34 \%$ & $75.72 \%$ & $79.10 \%$ & $75.39 \%$ \\
& $(47.87 \%, 80.46 \%)$ & $(62.20 \%, 82.88 \%)$ & $(62.69 \%, 83.57 \%)$ & $(71.43 \%, 86.97 \%)$ & $(69.47 \%, 85.22 \%)$ \\
Idio & $29.80 \%$ & $22.66 \%$ & $24.28 \%$ & $20.91 \%$ & $24.61 \%$ \\
& $(19.54 \%, 52.13 \%)$ & $(17.12 \%, 37.80 \%)$ & $(16.43 \%, 37.32 \%)$ & $(13.04 \%, 28.57 \%)$ & $(14.78 \%, 30.53 \%)$ \\
\hline
\end{tabular}

NOTES: Same as Table 4. 
Table 16: U.S. GDP Growth Regressions

\begin{tabular}{|c|c|c|c|c|c|}
\hline & \multicolumn{2}{|c|}{ Whole Sample } & \multirow[b]{2}{*}{$(3)$} & \multicolumn{2}{|c|}{ Gabaix Restrictions } \\
\hline & (1) & $(2)$ & & $(4)$ & $(5)$ \\
\hline & $\Xi$ & $\Gamma$ & $G$ & $\Xi$ & $\Gamma$ \\
\hline \multirow[t]{2}{*}{ Constant } & 0.009 & 0.0076 & 0.0074 & 0.009 & 0.009 \\
\hline & $(0.007,0.01)$ & $(0.0067,0.0088)$ & $(0.0071,0.0076)$ & $(0.008,0.01)$ & $(0.008,0.009)$ \\
\hline \multirow[t]{2}{*}{$x_{t}$} & 0.12 & 0.04 & 0.059 & 0.48 & 0.29 \\
\hline & $(0.07,0.16)$ & $(-0.03,0.15)$ & $(0.041,0.121)$ & $(0.37,0.59)$ & $(0.14,0.49)$ \\
\hline \multirow[t]{2}{*}{$x_{t-1}$} & 0.03 & -0.02 & 0.006 & 0.16 & 0.12 \\
\hline & $(-0.01,0.07)$ & $(-0.06,0.03)$ & $(0.001,0.017)$ & $(0.05,0.28)$ & $(0.07,0.17)$ \\
\hline \multirow[t]{2}{*}{$x_{t-2}$} & -0.02 & -0.005 & -0.004 & -0.05 & 0.11 \\
\hline & $(-0.06,0.02)$ & $\left(\begin{array}{lll}-0.03 & 0.02\end{array}\right)$ & $(-0.008,0.001)$ & $(-0.16,0.06)$ & $(0.02,0.19)$ \\
\hline \multirow[t]{2}{*}{$\operatorname{Adj} R^{2}$} & 0.13 & 0.016 & 0.28 & 0.38 & 0.13 \\
\hline & & $(0,0.04)$ & $(0,0.04)$ & & $(0.04,0.32)$ \\
\hline Observations & 197 & 197 & 197 & 197 & 197 \\
\hline
\end{tabular}

NOTES: Same as Table 5. 